\title{
HDACs class II-selective inhibition alters nuclear receptor-dependent differentiation
}

\author{
Angela Nebbioso ${ }^{1}$, Carmela Dell'Aversana ${ }^{1,2}$, Anne Bugge $^{3}$, Roberta Sarno $^{1}$, \\ Sergio Valente ${ }^{4}$, Dante Rotili ${ }^{4}$, Fabio Manzo ${ }^{1,5}$, Diana Teti ${ }^{2}$, Susanne Mandrup ${ }^{3}$, \\ Paolo Ciana ${ }^{6}$, Adriana Maggi ${ }^{6}$, Antonello Mai ${ }^{4}$, Hinrich Gronemeyer ${ }^{5}$ \\ and Lucia Altucci ${ }^{1,7}$ \\ ${ }^{1}$ Dipartimento di Patologia Generale, Seconda Università di Napoli, 80138 Napoli, Italy \\ ${ }^{2}$ Dipartimento di Patologia e Microbiologia Sperimentale, Università di Messina, via Consolare Valeria, 198125 Messina, Italy \\ ${ }^{3}$ University of Southern Denmark, DK-5230 Odense, Denmark \\ ${ }^{4}$ Dipartimento di Studi Farmaceutici, Università degli Studi di Roma 'La Sapienza', 00185 Roma, Italy \\ ${ }^{5}$ Department of Cancer Biology, Institut de Génétique et de Biologie Moléculaire et Cellulaire, BP 10142, Illkirch, France \\ ${ }^{6}$ Università degli Studi di Milano, I-20133 Milano, Italy \\ ${ }^{7}$ CNR-IGB, Via P. Castellino, 80100 Napoli, Italy \\ (Correspondence should be addressed to H Gronemeyer; Email: hg@igbmc.u-strasbg.fr; L Altucci; Email: lucia.altucci@ unina2.it)
}

\begin{abstract}
Epigenetic deregulation contributes to diseases including cancer, neurodegeneration, osteodystrophy, cardiovascular defects, and obesity. For this reason, several inhibitors for histone deacetylases (HDACs) are being validated as novel anti-cancer drugs in clinical studies and display important anti-proliferative activities. While most inhibitors act on both class I, II, and IV HDACs, evidence is accumulating that class I is directly involved in regulation of cell growth and death, whereas class II members regulate differentiation processes, such as muscle and neuronal differentiation. Here, we show that the novel class II-selective inhibitor MC1568 interferes with the RAR- and peroxisome proliferator-activated receptor $\gamma($ PPAR $\gamma)$-mediated differentiation-inducing signaling pathways. In F9 cells, this inhibitor specifically blocks endodermal differentiation despite not affecting retinoic acid-induced maturation of promyelocytic NB4 cells. In 3T3-L1 cells, MC1568 attenuates PPAR $\gamma$-induced adipogenesis, while the class I-selective MS275 blocked adipogenesis completely thus revealing a different mode of action and/or target profile of the two classes of HDACs. Using in vivo reporting PPRE-Luc mice, we find that MC1568 impairs PPAR $\gamma$ signaling mostly in the heart and adipose tissues. These results illustrate how HDAC functions can be dissected by selective inhibitors.
\end{abstract}

Journal of Molecular Endocrinology (2010) 45, 219-228

\section{Introduction}

In the past years, epigenetic therapies have come of age. The finding that histone deacetylases (HDACs) often are more expressed in tumor cells gave credit to the application of HDAC inhibitors (HDACIs) to target cancer cells, without affecting the normal ones. In humans, HDACs class I - the RPD3/HDA1 family - comprises HDAC1, HDAC2, HDAC3, and HDAC8, whereas class IIa includes HDAC4, HDAC5, HDAC7, and HDAC9, and class IIb includes HDAC6 and HDAC10. Members of class I are homologous to yeast RPD3, while class II HDACs are related to the yeast HDA1. HDAC11, which shows homology to both RPD3 and HDA1, has been allocated to the separate class IV. The third HDAC class includes sirtuins, characterized by $\mathrm{NAD}^{+}$-dependent activity, differently from the other HDACs. With their ability to deacetylate histones, HDACs compact chromatin, thus regulating heterochromatin formation and maintenance. In addition, many HDACs have 'non-histone' targets, such as p53 (Bode \& Dong 2004), NFKB (Chen et al. 2002, Furia et al. 2002), several nuclear receptors (NRs; Wang et al. 2001), and cofactors (Rodgers et al. 2005). In this context, it is interesting to note that acetylation modulates NR binding to chromatin and/or to factors involved in mediating NR functions. The implication of HDACs in cancer etiology and therapy has been revealed in both solid tumors and leukemias (Monneret 2005, Nebbioso et al. 2005). For example, suberoylanilide hydroxamic acid (SAHA), a class I-II HDACI, has been approved in 2006 by the FDA for the treatment of cutaneous T-cell lymphomas.

The HDACI MC1568 selectively inhibits the HDAC classes IIa and b (Mai et al. 2005, Nebbioso et al. 2009). 
Class II HDACs appear to be mainly involved in the regulation of differentiation, such as myogenesis (Lu et al. 2000), neuronal differentiation (Chawla et al. 2003), and osteogenesis (Hug 2004). Mechanistically, class IIa members may compete with the histone acetyltransferase p300 for direct binding to the myocyte enhancer factor 2 (MEF2), thus potentially modulating myocyte differentiation. Moreover, HDAC4 null mice display skeletal defects possibly linked to altered Runx2 action (Vega et al. 2004), while knockout of HDAC5 or HDAC9 displays cardiac hypertrophy (Chang et al. 2004, McKinsey \& Olson 2004, 2005). The class IIb HDAC6 displays distinct functionality, as its inhibition stimulates tubulin acetylation and influences cell motility (Hubbert et al. 2002, Palazzo et al. 2003, Zhang et al. 2003).

Both class I and II HDACs are involved in the regulation of transcription by NRs such as ER $\alpha$ (ESR1), RAR $\alpha$, or peroxisome proliferator-activated receptor $\gamma$ (PPAR $\gamma)$. The binding of HDACs to NR-recruited co-repressors, such as SMRT and NCOR, is thought to mediate the repression of target genes seen in the absence of agonists. The multi-subunit complex formed by the co-repressors HDAC4 or HDAC5 and HDAC3 has been studied extensively in several cellular systems (Karagianni \& Wong 2007).

Here, we report on the effects of the selective inhibition of class II HDAC activity in three models of NR-regulated differentiation. The first comprises the F9 mouse embryonic carcinoma cells, derived from an experimentally induced teratocarcinoma (Berstine et al. 1973). Upon treatment with all-trans retinoic acid (ATRA), F9 cells differentiate into endodermaltype cells in monolayer cultures. By various criteria, these cells have been shown to correspond to parietal endodermal cells. The efficiency of differentiation of parietal endoderm-like cells can be stimulated by adding dibutyryl cyclic AMP to the culture medium. F9 cells can also differentiate into visceral endoderm-type cells in the presence of retinoic acid under nonadherent condition. The second model comprises NB4 cells, a prototypic model for human acute promyelocytic leukemia (Altucci \& Gronemeyer 2001). The third is the murine 3T3-L1 adipogenesis model. The master regulator of this latter process is the NR PPAR $\gamma$, the absence of which totally abrogates differentiation (Liao et al. 2007). Finally, in order to reveal the action of MC1568 in vivo, we have used engineered PPAR $\gamma$ 'reporter' mice to investigate the possible regulation of PPAR $\gamma$ signaling by class II HDACs. Altogether our results reveal an as yet unrecognized activity spectrum of class II HDACs, as MC1568 inhibits F9 cell endodermal, but not NB4 promyelocytic, differentiation by retinoids and attenuates PPAR $\gamma$ activity both in cell lines and in vivo.

\section{Materials and methods}

\section{Ligands and chemicals}

MS275 (Bayer-Schering) was dissolved in ethanol and used at $5 \mu \mathrm{M}$; MC1568 HPLC purified was synthesized as described (Mai et al. 2005, Nebbioso et al. 2009), dissolved in DMSO, and used at 1,5 or $10 \mu \mathrm{M}$ as indicated. Troglitazone was a gift of Bristol-Myers-Squibb, rosiglitazone (BRL 49653) was a gift of Novo Nordisk (Rome, Italy); dibutyryl cAMP, ATRA, dexamethasone, and insulin were obtained from Sigma.

\section{Cell lines and cultures}

F9 cells were maintained in DMEM supplemented with $10 \% \mathrm{FCS}$ and $1 \mathrm{mg} / \mathrm{l}$ gentamicin and $2 \mathrm{mM}$ glutamine. The F9 cells periodically were grown in bacteria plates like aggregates for 2-3 days and after put in plates coated with $0 \cdot 1 \%$ gelatin. The 3T3-L1 cells were propagated and differentiated using a differentiation cocktail consisting of isobutylmethylxanthine, dexamethasone, and insulin (MDI) as previously described (Nielsen et al. 2008, Kim et al. 2009). From the second day post-confluence and throughout the differentiation period of 8 days, the cells were subjected to either DMSO, 5 or $10 \mu \mathrm{M}$ MC1568, or $5 \mu \mathrm{M}$ MS275. For the experiments where the three differentiation media were compared, the 3T3-L1 mouse fibroblasts were kept as follows: i) no induction: at post-confluence and throughout the differentiation period of 8 days, the cells were incubated with DMSO, 5 or $10 \mu \mathrm{M}$ MC1568, or $5 \mu \mathrm{M}$ MS275. Medium was renewed every second day. ii) Induction with troglitazone: at post-confluence and throughout the differentiation period of 8 days, the cells were induced with $5 \mu \mathrm{M}$ troglitazone, $5 \mu \mathrm{M}$ MC1568, or both. iii) Induction by rosiglitazone: at post-confluence and throughout the differentiation period of 8 days, the cells were incubated with $1 \mu \mathrm{M}$ of rosiglitazone and either DMSO, 5 or $10 \mu \mathrm{M}$ MC1568, $5 \mu \mathrm{M}$ MS275, or $125 \mathrm{nM}$ trichostatin A(TSA). Medium was renewed every second day. iv) Induction by rosiglitazone and dexamethasone: at post-confluence, the cells received $1 \mu \mathrm{M}$ of rosiglitazone and $390 \mathrm{ng} / \mathrm{ml}$ dexamethasone dissolved in abs. EtOH. Throughout the differentiation period of 8 days, the cells were induced with $1 \mu \mathrm{M}$ of rosiglitazone and either DMSO, 5 or $10 \mu \mathrm{M}$ MC1568, $5 \mu \mathrm{M}$ MS275, or $125 \mathrm{nM}$ TSA. Medium was renewed every second day.

\section{Fluorimetric human recombinant HDAC1 and HDAC4 in vitro assays}

HDAC1 and 4 assays were performed as previously described (Lahm et al. 2007, Nebbioso et al. 2009). For HDAC4, the non-histone substrate 'trifluoroacetyl lysine' was used as in Lahm et al. (2007). 


\section{Oil red $O$ staining}

This assay was performed following standard procedures. 3T3-L1 cells were fixed with $3 \cdot 7 \%$ formaldehyde for $10 \mathrm{~min}$ and then stained with oil red $\mathrm{O}$ for $1 \mathrm{~h}$ followed by washing with $70 \%$ methanol and water.

\section{NBT assay}

For the NBT reduction assay, $500 \mu \mathrm{l}$ medium containing $1 \times 106$ cells were mixed with $500 \mu \mathrm{l}$ of $0 \cdot 2 \%$ NBT and $200 \mathrm{ng} 12-O$-tetradecanoylphorbol-13-acetate (Sigma). After incubation for $30 \mathrm{~min}$ at $37^{\circ} \mathrm{C}$, the liquid was discarded, cells and formazan deposits were lysed by $500 \mu \mathrm{l}$ of lysis buffer ( $50 \%$ dimethylformamide and $20 \%$ SDS, pH 7.4), and optical density was measured on a spectrophotometer at $570 \mathrm{~nm}$.

\section{RT-PCR, real-time PCR, and primers}

Total RNA was extracted from 3T3-L1 cells and F9 cells (Trizol). Two micrograms of total RNA were reverse transcribed using superscript VILO (Invitrogen). For amplification, we used the following primers: laminin B1, forward (5'-ACAACACCAAAGGCCTGAAC- $\left.3^{\prime}\right)$ and reverse $\left(5^{\prime}\right.$-TGCCAGTAGCCAGGAAGACT- $\left.3^{\prime}\right)$; collagen IV, forward (5'-ACAACAGARGACCCACTGTG-3 $3^{\prime}$ ) and reverse (5'-GTGTGCATCACGAAGGAATA-3'); SPARC, forward (5'-GTCCCACACTGAGCTGGC- $\left.3^{\prime}\right)$ and reverse (5'-AAGCACAGAGTCTGGGTGAGTG-3'); adiponectin, forward (5'-AGGGTGAGACAGGAGATGTTGGAAT- $\left.3^{\prime}\right)$ and reverse (5'-GCCAGTAAATGTAGAGTCGTTGACGT-3'); A-FABP (aP2), forward (5'-AACACCGAGATTTCCTTCAAACTG- $\left.3^{\prime}\right)$ and reverse $\left(5^{\prime}\right.$-TCACGCCTTTCATAACACATTCCA- $\left.3^{\prime}\right)$; actin, forward ( $5^{\prime}$-GACGGCCAGGTCATCACTAT- $\left.3^{\prime}\right)$ and reverse (5'-CCACCGATCCACACAGAGTA- $\left.3^{\prime}\right) ; P P A R \gamma$, forward $\left(5^{\prime}\right.$-TCTCTCCGTAATGGAAGACC- $\left.3^{\prime}\right)$ and reverse (5'-GCATTATGAGACATCCCCAC-3 ${ }^{\prime}$ ); thrombomodulin, forward ( $5^{\prime}$-TGGAGCATGAGTGCTTCGC- $\left.3^{\prime}\right)$ and reverse ( $5^{\prime}$-GGTGTTGTAGGTACTAGAGA-3' $)$; $G A P D H$, forward (5'-TCAACGGGAAGCCCATCACCA- $3^{\prime}$ ) and reverse (5'-ACGGAAGGCCATGCCAGTGA-3'). Real-time PCR was performed with the following primers: TFIIB, forward (5'-GTTCTGCTCCAACCTTTGCGT- $3^{\prime}$ ) and reverse (5'-TGTGTAGCTGCCATCTGCACTT-3' ${ }^{\prime}$ ); A-FABP (aP2), forward (5'-CTG GGCGTGGAATTCGAT- $3^{\prime}$ ) and reverse (5'-GCTCTTCACCTTCCTGTCGTCT- $\left.3^{\prime}\right)$; adiponectin, forward (5'-TGACTGCAACTACCCATAGC- $\left.3^{\prime}\right)$ and reverse $\left(5^{\prime}\right.$-TTAATGAACAAGTGAGTACACG-3 $3^{\prime}$ ); leptin, forward $\left(5^{\prime}\right.$-TGTGCTGCAGATAGCCAATGA-3 $3^{\prime}$ ) and reverse (5'-AGATGGAGGAGGTCTCGGAGA-3'); $C / E B P \alpha$, forward (5'-CAAGAACAGCAACGAG TACCG-3 $\left.3^{\prime}\right)$ and reverse (5'-GTCACTGGTCAACTCCAGCAC-3'); actin, forward ( $5^{\prime}$-GACGGCCAGGTCATCACTAT-3') and reverse (5'-CCACCGATCCACACAGAGTA-3' $)$; laminin B1, forward (5'-ACAACACCAAAGGCCTGAAC-3') and reverse (5'-TGCCAGTAGCCAGGAAGACT-3 $\left.{ }^{\prime}\right)$; SPARC, forward ( $5^{\prime}$-GAGGAGGTGGTGGCTGACAA- $\left.3^{\prime}\right)$ and reverse ( $5^{\prime}$-CACCTTGCCATGTTTGCAAT- $3^{\prime}$ ); collagen IV, forward (5'-ACAACAGAGACCCACTGTG-3') and reverse (5'-GTGTGCATCACGAAGGAATA- $\left.3^{\prime}\right)$; PPAR $\gamma$, forward $\left(5^{\prime}\right.$-TTTTCAAGGGTGCCAGTTTC-3 $\left.{ }^{\prime}\right)$ and reverse ( $5^{\prime}$-AATCCTTGGCCCTCTGAGAT- $3^{\prime}$ ); thrombomodulin, forward (5'-TGGAGCATGAGTGCTTCGC-3') and reverse ( $5^{\prime}$-GGTGTTGTAGGTACTAGAGA-3' ${ }^{\prime}$.

\section{Use of the PPRE-Luc transgenic mouse}

The PPRE-Luc transgenic mouse has been previously described (Ciana et al. 2007, Biserni et al. 2008); in this reporter mouse model, luciferase expression is modulated by PPAR ligands and can be considered a surrogate marker for PPAR transcriptional activation. For optical imaging studies, mice were first anesthetized using an s.c. injection of $50 \mu \mathrm{l}$ ketamine-xylazine solution composed of $78 \%$ ketamine (Ketavet 50, Intervet, Peschiera Borromeo, Italy), $15 \%$ xylazine (Rompun 2\% solution, Bayer), and $7 \%$ water, and then received an i.p. injection of $25 \mathrm{mg} / \mathrm{kg}$ D-luciferin ( $25 \mathrm{mg} / \mathrm{kg}$; Promega); to obtain a uniform biodistribution of the substrate, CCD camera detection was performed $20 \mathrm{~min}$ after luciferin injection (Ciana et al. 2003, 2007). Bioluminescence measurements were done with a Night Owl imaging unit (Berthold Technologies, Bad Wildbad, Germany) consisting of a Peltier cooled charge-coupled device slow-scan camera equipped with a $25 \mathrm{mmf} / 0.95$ lens. Images were generated by a Night Owl LB981 image processor and transferred via video cable to a peripheral component interconnect frame grabber using WinLight32 software (Berthold Technologies). To lower the background activity of endogenous PPAR activities due to dietary intake of lipids, experimental mice were fed solely during the night (Ciana et al. 2007), and photon emission was measured at $1700 \mathrm{~h}$. In chronic studies, $50 \mathrm{mg} / \mathrm{kg}$ MC1568 and $5 \mathrm{mg} / \mathrm{kg}$ of rosiglitazone or vehicle (water solution of $0.5 \%$ carbossimetilcellulose) were administered by gavage once a day at $0900 \mathrm{~h}$, for a total of 7 days starting from day 1. In co-treatment, MC1568 was administered $30 \mathrm{~min}$ before rosiglitazone. Photon emission was measured in chest and abdomen; photon emission from these areas is due mainly to liver and intestine as demonstrated in preliminary experiments (data not shown and Ciana et al. (2007)).

\section{Luciferase enzymatic assay}

Mice were euthanized and dissected, and tissues were immediately frozen on ice. Protein extracts were

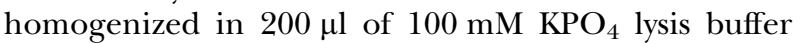
( $\mathrm{pH} 7.8$ containing $1 \mathrm{mM}$ dithiothreitol, $4 \mathrm{mM}$ EGTA, $4 \mathrm{mM}$ EDTA, and $0.7 \mathrm{mM}$ phenylmethylsulfonyl 
fluoride), three cycles of freezing-thawing, and $30 \mathrm{~min}$ of minifuge centrifugation (Eppendorf, Hamburg, Germany) at maximum speed. Supernatants containing luciferase were collected, and protein concentrations were determined by Bradford's assay. Luciferase enzymatic activity was measured by a commercial kit (Luciferase assay system, Promega) according to the supplier's instructions. Light intensity was measured with a luminometer (Veritas, Promega) over $10 \mathrm{~s}$ time periods and expressed as relative light units per $\mu \mathrm{g}$

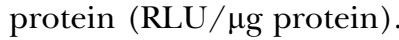

\section{Results}

\section{The class II HDACI MC1568 blocks differentiation in a cell-specific manner}

Supporting the notion that class II HDACs may function primarily during specific cell physiological events, several class II HDACs interact with factors involved in cell differentiation (Verdin et al. 2003, Yang \& Gregoire 2005). To assess directly the role of class II HDACs on cell differentiation, we investigated the effect of the class II-selective HDACI MC1568 (Fig. 1A) in well-established models, namely primitive or parietal endodermal differentiation (Rochette-Egly \& Chambon 2001), NB4 promyelocytic maturation (Altucci \& Gronemeyer 2001), and adipogenesis (Rangwala \& Lazar 2000). Note that the complete characterization of the inhibitory action of the MC1568 has been previously reported (Nebbioso et al. 2009).

Exposure of F9 embryonal carcinoma cells to ATRA induced primitive endodermal differentiation that was blocked by MC1568 as revealed by cell morphology (Fig. 1B, top panel) and confirmed by the lack of induction of the differentiation marker collagen IV (Fig. 1C and D). The same differentiation block was observed for parietal endodermal differentiation induced by ATRA and cAMP (Fig. 1B, bottom panel). Indeed, the de novo induction of thrombomodulin (Weiler-Guettler et al. 1992) and the enhanced expression of SPARC, collagen IV, and laminin $\mathrm{B} 1$ were all impaired in the presence of MC1568 (Fig. 1C and D).

While these observations supported the hypothesis that class II-selective HDAC inhibition antagonized retinoic acid signaling, no such effects were seen in another retinoid-induced cellular differentiation system. Indeed, in stark contrast to F9 cells, the ATRAinduced maturation of NB4 promyelocytic leukemia cells was entirely unaffected by the HDAC class II-selective inhibitor (Fig. 1E) after treatment for $96 \mathrm{~h}$. Thus, retinoic acid signaling apparently involves class II HDAC action in a cell-specific manner, possibly due to differential expression of HDACs and/or different functional role of HDACs in the retinoic acid signaling pathway.

\section{HDAC class II inhibition decreases PPAR $\gamma$-dependent adipogenesis, while class I inhibitors block adipogenesis completely}

Complex transcriptional hierarchies govern the changes and maintenance of cell morphology and gene expression associated with adipogenesis (Chen et al. 2005). Transcription factors form cross-regulatory circuits and act in concert with epigenetic programs (Yoo \& Jones 2006) that can be altered by HDACIs (Lagace \& Nachtigal 2004, Qiao et al. 2006). Interestingly, our data indicate that class II HDACs are involved in the regulation of adipogenesis, as MC1568 inhibits the adipogenic activity of troglitazone in 3T3L1 preadipocytes, as verified by oil red $\mathrm{O}$ staining (Fig. 2A) and induction of differentiation markers (Fig. 2B). Most likely, this effect results from the attenuation of troglitazone-induced PPAR $\gamma$ expression by MC1568 (Fig. 2G). Interestingly, the class I-selective HDACI MS275 blocks PPAR $\gamma$ induction (Fig. 2C) and adipogenesis (Fig. 2D) completely. In contrast to MS275 (Fig. 2D), even at higher concentration equal to $10 \mu \mathrm{M}$, complete differentiation medium can partially override the adipogenesis block imposed by MC1568 (Fig. 2D, lower panel). The activation of the aP2 and adiponectin differentiation markers is blocked by MC1568 after induction of adipogenesis with troglitazone or rosiglitazone (Fig. 3A), whereas the activation of these same targets is unaffected in the presence of complete differentiation medium or the combination of rosiglitazone and dexamethasone (Fig. 3B-C). Note that both troglitazone and rosiglitazone have been reported to similarly induce 3T3L1 adipocyte differentiation (Huang et al. 2006). Moreover, we note that while the differentiation markers aP2, adiponectin, and $\mathrm{C} / \mathrm{EBP} \alpha$ are unaffected by exposure to MC1568 (Fig. 3B, C, and E), the expression of leptin is significantly down-regulated (Fig. 3D) in both rosiglitazone and MDI-induced differentiation of 3T3-L1 cells. Thus, HDAC class II inhibitors seem to interfere with a subset of gene programs associated with adipogenesis.

\section{HDAC class II inhibition exerts organ-selective effects on PPAR $\gamma$ signaling in vivo}

Given that MC1568 attenuated adipogenesis in vitro in pro-adipogenic 3T3L1 cells, the possible effect of the drug was assessed in the PPRE-Luc PPAR reporter mouse model in vivo with the idea of exploring a possible anti-obesity activity. In this reporter, mouse luciferase expression is activated in response to PPAR agonists in cognate target organs (Ciana et al. 2007, 
A
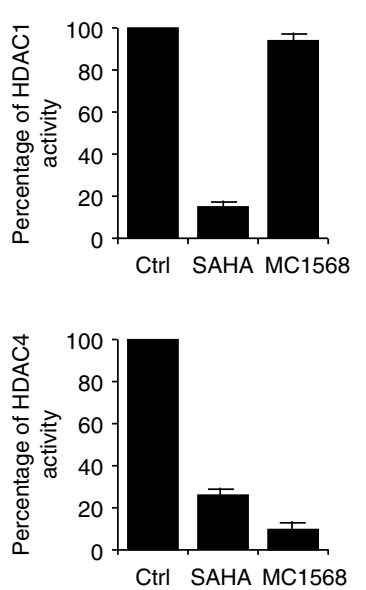

B

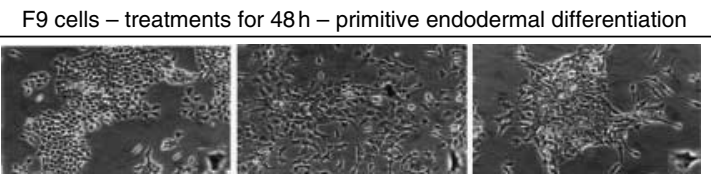

Control

ATRA

ATRA + MC1568

F9 cells - treatments for $96 \mathrm{~h}$ - parietal endodermal differentiation

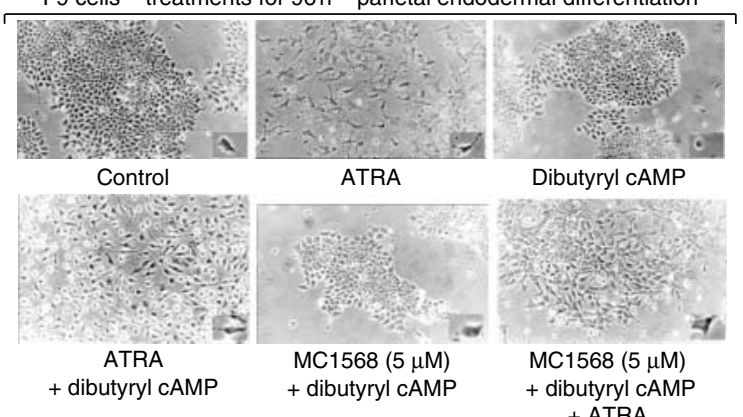

+ ATRA

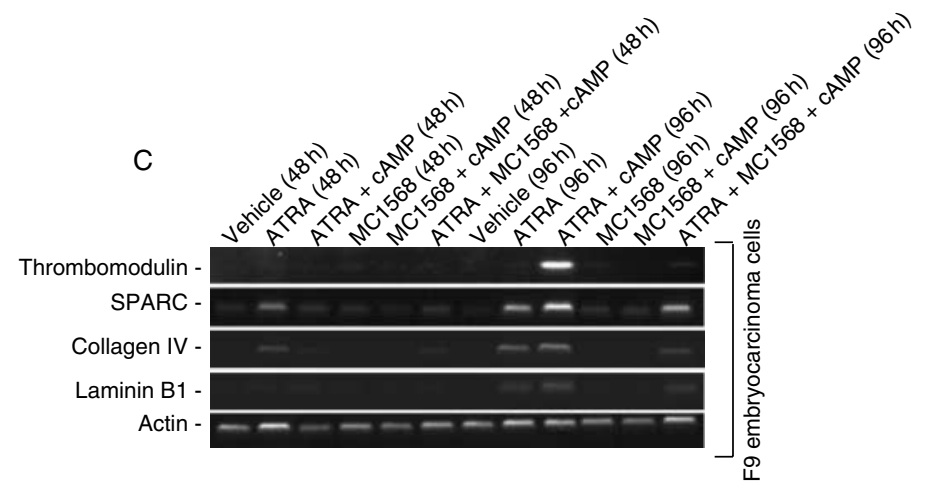

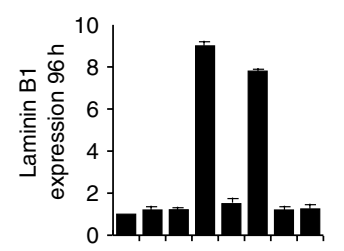

MC1568 - + - - + - + +

CAMP --+--+++

ATRA $\quad---+++-+$

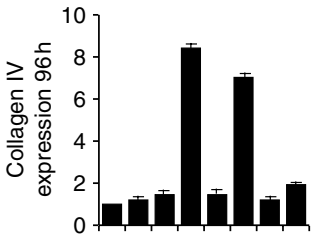

MC1568

CAMP

ATRA

$\mathrm{D}$

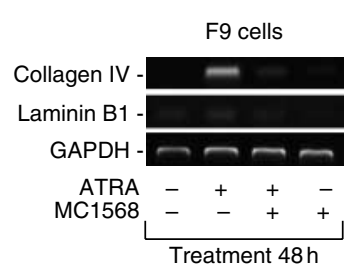

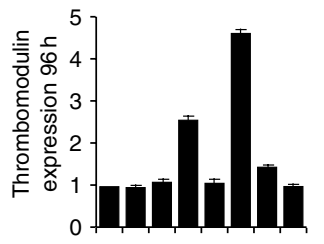

MC1568

--+-+++ CAMP

ATRA

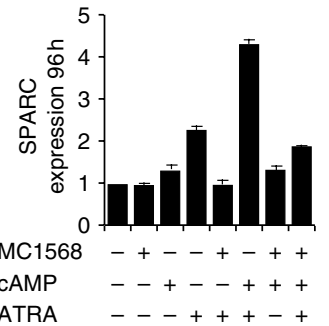

--+-+++ CAMP

ATRA

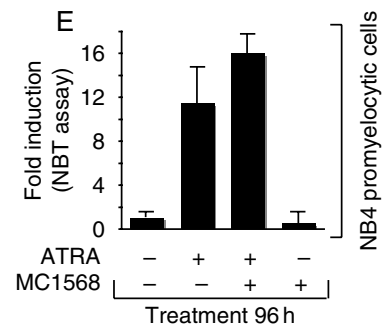

Figure 1 The class II-selective HDAC inhibitor MC1568 blocks retinoic acid-induced F9 cell differentiation, but not promyelocytic NB4 cell maturation. (A) In vitro human recombinant HDAC1 and HDAC4 assays with or without MC1568 or SAHA used at $5 \mu$ M; for HDAC4 assay, the specific trifluoroacetyl lysine substrate has been used; (B) morphological analysis of F9 cells upon treatment with MC1568 in combination with ATRA and cAMP at the indicated time; (C) RT-PCR and qPCR of molecular differentiation markers in F9 cells treated as indicated; (D) RT-PCR of collagen IV and laminin B1 in F9 cells treated as indicated; (E) NBT differentiation assay carried out in NB4 cells treated as described. 


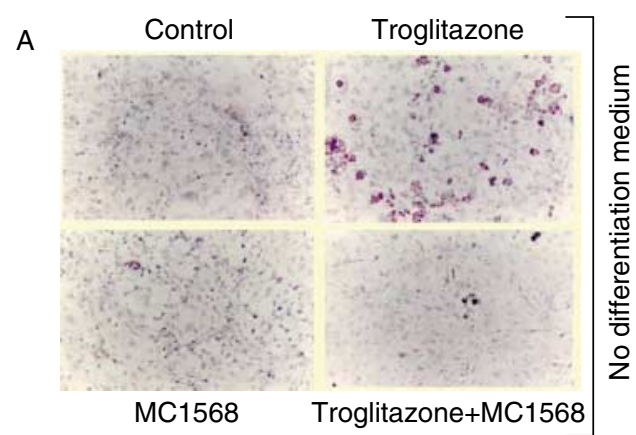

B
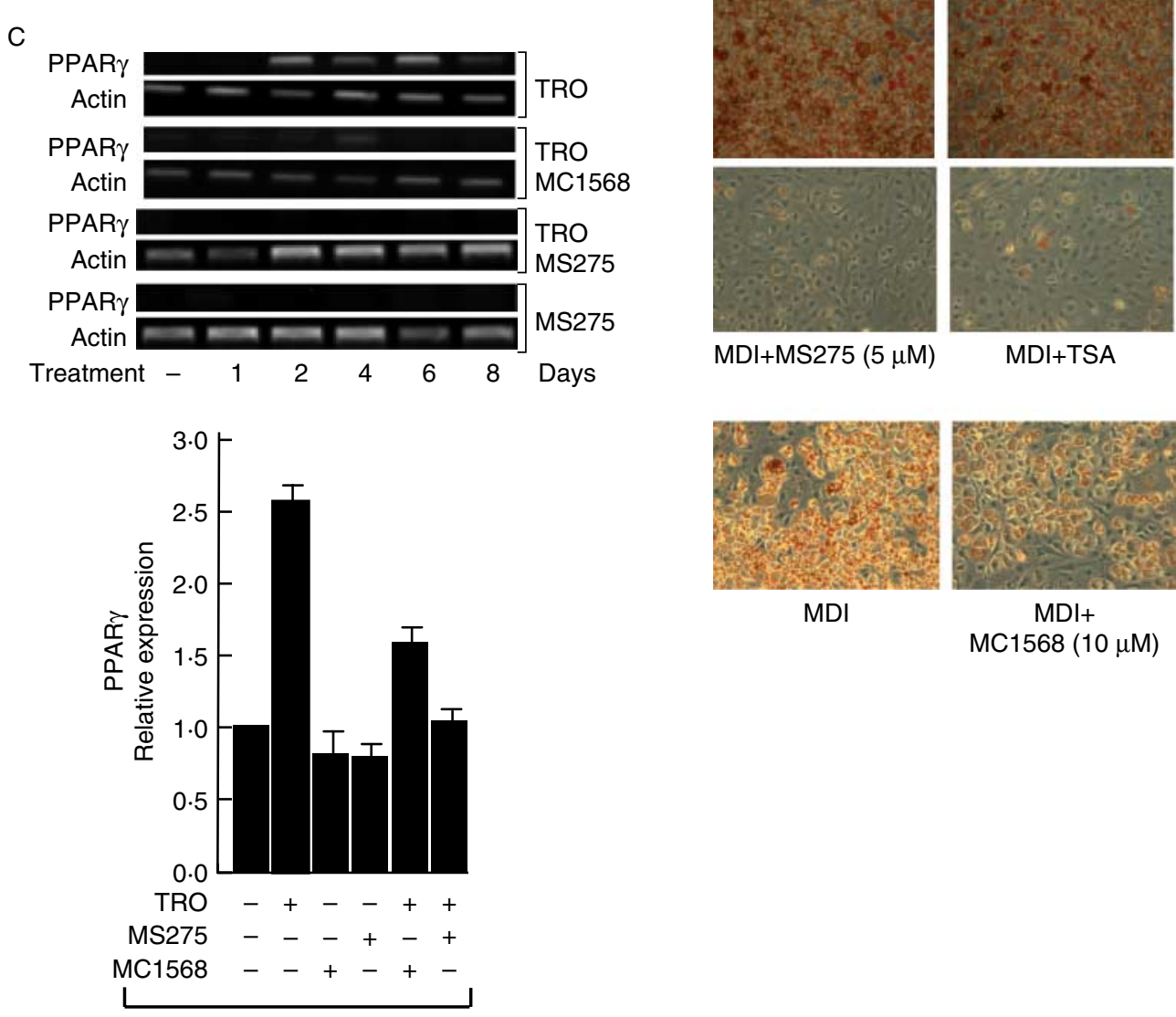

Day 6

Figure 2 MC1568 attenuates TZD-induced PPAR $\gamma$ induction and adipogenesis of 3T3-L1 cells, while pan-HDAC inhibitors block differentiation completely. (A) Morphological analysis obtained with oil red $\mathrm{O}$ staining and (B) RT-PCR of molecular differentiation markers in 3T3-L1 cells treated as indicated; (C) RT-PCR of PPAR $\gamma$ expression in the 3T3-L1 cells treated as indicated; (D) morphological analysis obtained with oil red O staining of 3T3-L1 cells in complete differentiation medium and treated with TSA at $125 \mathrm{nM}$ and with MS275 or MC1568 at 5 or $10 \mu \mathrm{M}$. TRO, troglitazone; DEX, dexamethasone; MDI, differentiation cocktail consisting of isobutylmethylxanthine, dexamethasone, and insulin.

Biserni et al. 2008). Using whole body optical imaging, 7 days of treatment resulted in only minor changes between the various treatment groups (Fig. 4A). Indeed, quantification of bioluminescence did not show any significant effect of the agonist (rosiglitazone) or MC1568 with a trend towards a decrease in the overall photon emission upon co-treatment with both molecules in the chest but not in the abdomen (Fig. 4B). The limited effect of treatments in whole body bioluminescence emission after 7 days of rosiglitazone treatment may be ascribed to the high background activity of PPAR $\alpha$ and $\beta / \delta$ isoforms in the liver and intestine, the two most visible PPAR target organs in optical imaging experiments on PPRE-Luc mice. In contrast, ex vivo 

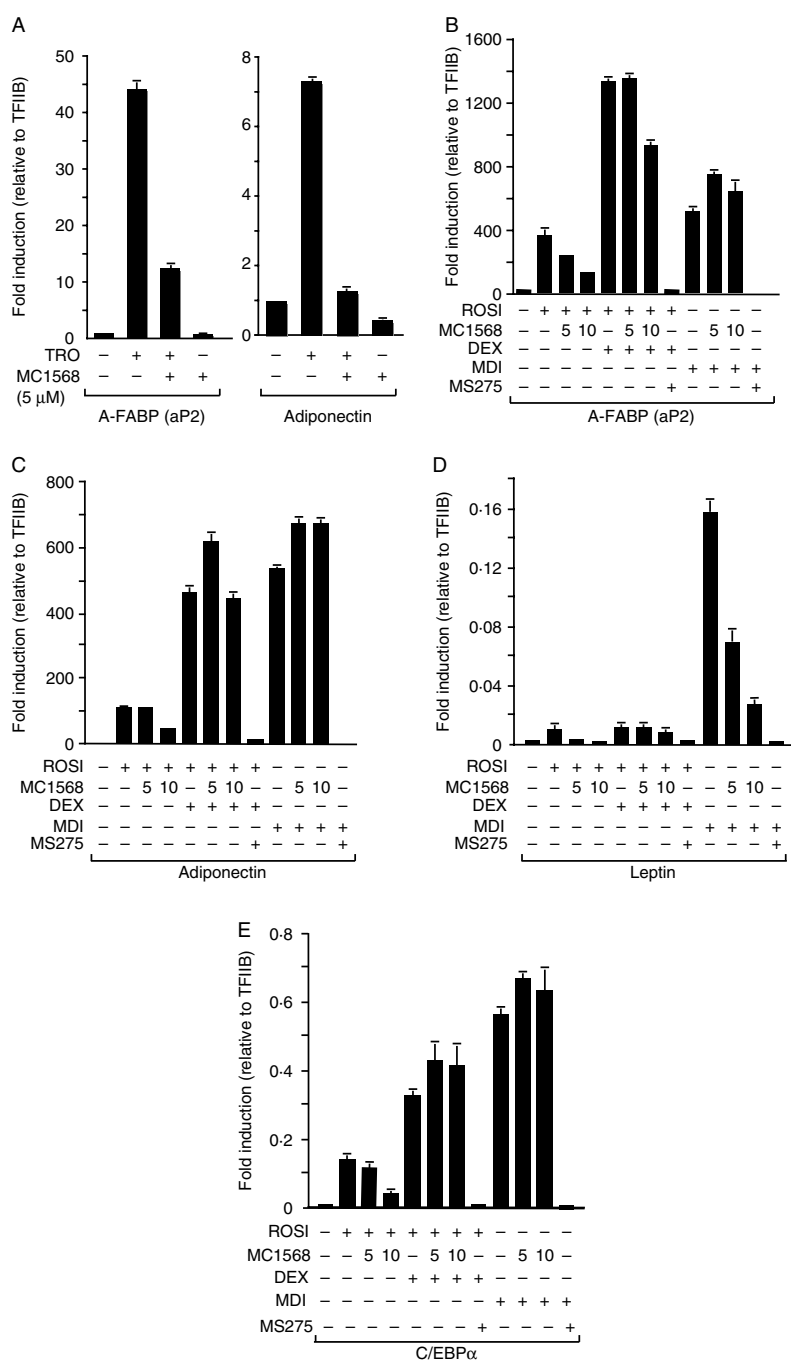

Figure 3 Expression levels of adipogenesis markers determined by real-time PCR. (A) A-FABP/aP2 and adiponectin expression levels relative to those of TFIIB by RT-qPCR in 3T3-L1 cells after the indicated treatments in the absence of MDI; (B-E) A-FABP/aP2 (B), adiponectin (C), leptin (D), and C/EBP $\alpha$ (E) expression levels measured relative to those of TFIIB by RT-qPCR in 3T3-L1 cells after the indicated treatments in the presence of MDI. ROS1, rosiglitazone; TRO, troglitazone; DEX, dexamethazone.

quantification of individual organs revealed a strikingly different picture. While no significant drug effects on reporter gene activity were measured in the intestinal compartment, administration of rosiglitazone or MC1568 alone revealed a trend towards lower activities in the liver, and co-administration of the two drugs resulted in significantly decreased liver luciferase expression (Fig. 4C). Most strikingly luciferase activity in the other PPAR $\gamma$ target organs, heart, and perirenal adipose tissue was strongly induced by rosiglitazone, and this induction was completely abolished by co-treatment with MC1568 (Fig. 4C bottom panels). These results indicate that the class II HDACI MC1568 can antagonize rosiglitazone activity in PPAR $\gamma$ target organs in vivo.

\section{Discussion}

While two HDACIs (SAHA (vorinostat) and depsipeptide) are in use for cancer therapy and others are enrolled in clinical trials, the clinical indications for HDAC subtype-selective modulators - which conceptually should display a reduced spectrum of side effects - have still to be determined. Given the ability of HDAC1 to repress Myo D and class II HDACs to block MEF2 target gene expression, it could be predicted that pharmacological HDAC inhibition would stimulate muscle gene expression and thus enhance myogenesis. Paradoxically, the same inhibitors were later reported to modulate skeletal muscle differentiation in a stagespecific manner revealing that HDACIs have the potential to enhance myogenesis (Iezzi et al. 2002). Inhibitory effects of HDACIs were reported for adipocyte differentiation. Treatment with class 1-selective or pan-HDACIs blocked the differentiation of 3T3-L1 cells (Kim et al. 2009) as confirmed in the present study.

That class II HDAC activity is required for some steps within the cascade of gene regulatory events that constitute a differentiation program is supported by our data on the retinoic acid induction of endodermal differentiation of F9 cells. Moreover, in studying the effects of class II HDACs in two different NR-dependent differentiation systems, we show that the class II-specific inhibitor MC1568 interferes with the transcriptional signaling of RARs as well as PPAR $\gamma$. That we are able to interfere with retinoic acid-mediated endodermal differentiation in F9 cells by altering the transcriptional regulation of target genes such as the collagen IV but that retinoic acid-mediated maturation of NB4 promyelocytes is not affected indicates that class II HDACs and their cognate inhibitors can exert tissue-specific effects. This observation is in keeping with class II HDACs-restricted expression in selected organs and tissues, and a stage-specific requirement of certain HDACs or HDAC classes may also account for the divergent observations reported for pan-HDACIs on myogenesis. Moreover, note that NB4 cells express limited amounts of selected class II HDACs. Selective HDAC class II inhibition blocks the (weak) differentiation of 3T3-L1 pre-adipocytes induced by troglitazone or rosiglitazone alone supposedly by inhibiting the induction of PPAR $\gamma$ expression. Notably, this block can be overridden by simultaneously activating several adipogenic pathways when using complete differentiation medium (MDI). Under such conditions, class II 


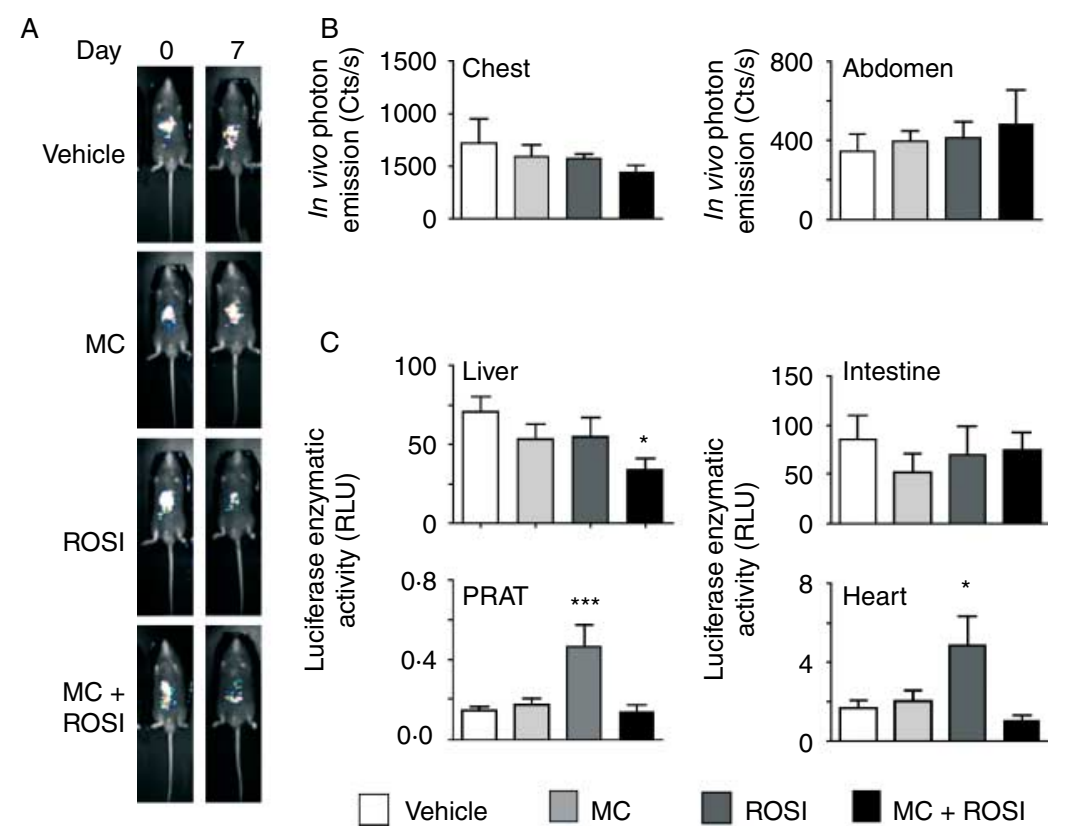

Figure 4 MC1568 antagonizes rosiglitazone-dependent induction of luciferase expression in adipose tissue and heart of the PPRE-Luc mouse. PPRE-Luc mice were treated by gavage daily with $5 \mathrm{mg} / \mathrm{kg}$ rosiglitazone (ROSI), $50 \mathrm{mg} / \mathrm{kg} \mathrm{MC1568} \mathrm{(MC),} \mathrm{or}$ vehicle (water solution of $0.5 \%$ carbossimetilcellulose); when co-administered, MC1568 was given 30 min before rosiglitazone for 7 days. Photon emission in chest and abdomen was measured at $1700 \mathrm{~h}$ at day 0 and at the end of the treatment (day 7). (A) Pictures of photon emission measured in vivo of a single, representative, individual at day 0 and 7. (B) Photon emission measured in vivo after 7 days treatment; bars represent the mean \pm S.E.M. (C) Luciferase contents from liver, intestine, perirenal adipose tissue (PRAT), and heart. Relative luciferase units (RLU, photon counts/ $\mu \mathrm{g}$ of proteins) were determined by enzymatic assay as described in Materials and methods. Bars represent the mean RLU \pm S.E.M. ${ }^{*} P<0.05$ and ${ }^{* * *} P<0.001$ versus vehicle-treated group.

inhibition results only in an attenuation of the efficiency of adipogenesis as determined by oil red $\mathrm{O}$ staining, suggesting both a direct and indirect involvement of class II HDACs in PPAR $\gamma$ signaling. The influence of HDAC class II on PPAR $\gamma$ signaling - and as a consequence the modulation of PPAR $\gamma$ by HDACIs (Kim et al. 2009) - might be explained both as a consequence of the interaction of HDACs with NRs (Franco et al. 2003) and of the influence on PPAR $\gamma$ target genes. That MC1568 also inhibits HDAC6 might suggest a role for HDAC6 in these settings. Despite HDAC6 contribution cannot be excluded, its main cytoplasm localization (Valenzuela-Fernández et al. 2008) does not fully support the interference with the PPAR $\gamma$ signaling pathway. Interestingly enough, the impairment of PPAR $\gamma$ signaling is supported by experiments in vivo with PPRE-Luc reporter mice, further arguing for a role of class II HDACs in mediating PPAR $\gamma$ signaling. Indeed, only the PPAR $\gamma$ 'target organs', such as the heart and adipose tissues, displayed inhibited PPAR $\gamma$ activity when animals were co-exposed to MC1568 and rosiglitazone. We also noted that inhibition of class II HDACs in the PPRE-Luc reporter mice did not lead to any side effects or detrimental alterations after administration of MC1568 as a single agent. Although PPAR $\gamma$ is expressed at low levels in many different cell types, it is well established that PPAR $\gamma$ activation in adipose tissue and to some extent also in macrophages is of key importance for the insulinsensitizing effects of thiazolidinediones (TZDs; Kahn et al. 2000, Hevener et al. 2007). However, PPAR $\gamma$ activation in other cell types may also contribute to the physiological effects of these TZDs including the side effects that limit the use of these drugs. Thus, treatment with TZDs such as rosiglitazone leads to edema in some patients (Nesto et al. 2003), and genetic experiments in mice indicate that the edema results from activation of PPAR $\gamma$ in the kidney epithelium (Zhang et al. 2005). Our observation that HDAC class II inhibition decreases TZD activation of PPAR $\gamma$ in cell culture as well as in vivo suggests that HDAC class II inhibition could potentially be used in combination with PPAR $\gamma$ agonists 
to modulate PPAR $\gamma$ activation in a tissue-specific manner. This would require that these inhibitors preferentially interfere with the deleterious side effects rather than the many beneficial effects of TZDs.

\section{Declaration of interest}

The authors declare that there is no conflict of interest that could be perceived as prejudicing the impartiality of the research reported.

\section{Funding}

This work was supported by the following EU projects: Epitron LSHC-CT2005-518417 (LA, HG, and AM); Apo-Sys HEALTHF2-2007-200620 (LA and HG); ATLAS HEALTH-F4-2009-221952 (HG and LA); X-TRA-NET LSHG-CT2005-018882 (HG and SM), by funds from the Associazione Italiana per la ricerca contro il cancro, AIRC (LA), the Fondazione ONLUS Luigi Califano (LA), PRIN 2008 (DT), and the Ligue Nationale Contre le Cancer (HG). FM was a French-Italian University $\mathrm{PhD}$ holder enrolled in the Vinci program.

\section{References}

Altucci L \& Gronemeyer H 2001 The promise of retinoids to fight against cancer. Nature Reviews. Cancer 1 181-193. (doi:10.1038/ 35106036)

Berstine EG, Hooper ML, Grandchamp S \& Ephrussi B 1973 Alkaline phosphatase activity in mouse teratoma. PNAS 70 3899-3903. (doi:10.1073/pnas.70.12.3899)

Biserni A, Giannessi F, Sciarroni AF, Milazzo FM, Maggi A \& Ciana P 2008 In vivo imaging reveals selective peroxisome proliferator activated receptor modulator activity of the synthetic ligand 3-(1-(4-chlorobenzyl)-3-t-butylthio-5-isopropylindol-2-yl)-2,2dimethylpropanoic acid (MK-886). Molecular Pharmacology 73 1434-1443. (doi:10.1124/mol.107.042689)

Bode AM \& Dong Z 2004 Post-translational modification of p53 in tumorigenesis. Nature Reviews. Cancer 4 793-805. (doi:10.1038/ nrc1455)

Chang S, McKinsey TA, Zhang CL, Richardson JA, Hill JA \& Olson EN 2004 Histone deacetylases 5 and 9 govern responsiveness of the heart to a subset of stress signals and play redundant roles in heart development. Molecular and Cellular Biology 24 8467-8476. (doi:10.1128/MCB.24.19.8467-8476.2004)

Chawla S, Vanhoutte P, Arnold FJ, Huang CL \& Bading H 2003 Neuronal activity-dependent nucleocytoplasmic shuttling of HDAC4 and HDAC5. Journal of Neurochemistry 85 151-159. (doi:10. $1046 / \mathrm{j} .1471-4159.2003 .01648 . \mathrm{x})$

Chen LF, Mu Y \& Greene WC 2002 Acetylation of RelA at discrete sites regulates distinct nuclear functions of NF-kappaB. EMBO Journal 21 6539-6548. (doi:10.1093/emboj/cdf660)

Chen Z, Torrens JI, Anand A, Spiegelman BM \& Friedman JM 2005 Krox20 stimulates adipogenesis via C/EBPbeta-dependent and -independent mechanisms. Cell Metabolism 1 93-106. (doi:10.1016/ j.cmet.2004.12.009)

Ciana P, Raviscioni M, Mussi P, Vegeto E, Que I, Parker MG, Lowik C \& Maggi A 2003 In vivo imaging of transcriptionally active estrogen receptors. Nature Medicine 9 82-86. (doi:10.1038/nm809)

Ciana P, Biserni A, Tatangelo L, Tiveron C, Sciarroni AF, Ottobrini L \& Maggi A 2007 A novel peroxisome proliferator-activated receptor responsive element-luciferase reporter mouse reveals gender specificity of peroxisome proliferator-activated receptor activity in liver. Molecular Endocrinology 21 388-400. (doi:10.1210/me. 2006-0152)

Franco PJ, Li G \& Wei L 2003 Interaction of nuclear receptor zinc finger DNA binding domains with histone deacetylase. Molecular and Cellular Endocrinology 206 1-12. (doi:10.1016/S03037207(03)00254-5)

Furia B, Deng L, Wu K, Baylor S, Kehn K, Li H, Donnelly R, Coleman T \& Kashanchi F 2002 Enhancement of nuclear factor-kappa B acetylation by coactivator p300 and HIV-1 Tat proteins. Journal of Biological Chemistry 277 4973-4980. (doi:10.1074/jbc.M107848200)

Hevener AL, Olefsky JM, Reichart D, Nguyen MT, Bandyopadyhay G, Leung HY, Watt MJ, Benner C, Febbraio MA, Nguyen AK et al. 2007 Macrophage PPAR gamma is required for normal skeletal muscle and hepatic insulin sensitivity and full antidiabetic effects of thiazolidinediones. Journal of Clinical Investigation 117 1658-1669. (doi:10.1172/JCI31561)

Huang C, Zhang Y, Gong Z, Sheng Z, Li Z, Zhang W \& Qin Y 2006 Berberine inhibits 3T3-L1 adipocyte differentiation through the PPAR $\gamma$ pathway. Biochemical and Biophysical Research Communications 348 571-578. (doi:10.1016/j.bbrc.2006.07.095)

Hubbert C, Guardiola A, Shao R, Kawaguchi Y, Ito A, Nixon A, Yoshida M, Wang XF \& Yao TP 2002 HDAC6 is a microtubule-associated deacetylase. Nature 417 455-458. (doi:10.1038/417455a)

Hug BA 2004 HDAC4: a corepressor controlling bone development. Cell 119 448-449. (doi:10.1016/j.cell.2004.10.023)

Iezzi S, Cossu G, Nervi C, Sartorelli V \& Puri PL 2002 Stage-specific modulation of skeletal myogenesis by inhibitors of nuclear deacetylases. PNAS 99 7757-7762. (doi:10.1073/pnas.112218599)

Kahn CR, Chen L \& Cohen SE 2000 Unraveling the mechanism of action of thiazolidinediones. Journal of Clinical Investigation 106 1305-1307. (doi:10.1172/JCI11705)

Karagianni P \& Wong J 2007 HDAC3: taking the SMRT-N-CoRrect road to repression. Oncogene 26 5439-5449. (doi:10.1038/sj.onc. 1210612)

Kim S, Choi H \& Kim Y 2009 Regulation of adipocyte differentiation by histone deacetylase inhibitors. Archives of Pharmacal Research 32 535-541. (doi:10.1007/s12272-009-1409-5)

Lagace DC \& Nachtigal MW 2004 Inhibition of histone deacetylase activity by valproic acid blocks adipogenesis. Journal of Biological Chemistry 279 18851-18860. (doi:10.1074/jbc.M312795200)

Lahm A, Paolini C, Pallaoro M, Nardi MC, Jones P, Neddermann P, Sambucini S, Bottomley MJ, Lo Surdo P, Carfi A et al. 2007 Unraveling the hidden catalytic activity of vertebrate class IIa histone deacetylases. PNAS 104 17335-17340. (doi:10.1073/pnas. 0706487104)

Liao W, Nguyen MT, Yoshizaki T, Favelyukis S, Patsouris D, Imamura T, Verma IM \& Olefsky JM 2007 Suppression of PPAR-gamma attenuates insulin-stimulated glucose uptake by affecting both GLUT1 and GLUT4 in 3T3-L1 adipocytes. American Journal of Physiology. Endocrinology and Metabolism 293 E219-E227. (doi:10. 1152/ajpendo.00695.2006)

Lu J, McKinsey TA, Zhang CL \& Olson EN 2000 Regulation of skeletal myogenesis by association of the MEF2 transcription factor with class II histone deacetylases. Molecular Cell 6 233-244. (doi:10.1016/ S1097-2765(00)00025-3)

Mai A, Massa S, Pezzi R, Simeoni S, Rotili D, Nebbioso A, Scognamiglio A, Altucci L, Loidl P \& Brosch G 2005 Class II (IIa)-selective histone deacetylase inhibitors. 1. Synthesis and biological evaluation of novel (aryloxopropenyl) pyrrolyl hydroxyamides. Journal of Medicinal Chemistry 48 3344-3353. (doi:10.1021/jm049002a)

McKinsey TA \& Olson EN 2004 Cardiac histone acetylation therapeutic opportunities abound. Trends in Genetics 20 206-213. (doi:10.1016/j.tig.2004.02.002)

McKinsey TA \& Olson EN 2005 Toward transcriptional therapies for the failing heart: chemical screens to modulate genes. Journal of Clinical Investigation 115 538-546. (doi:10.1172/JCI24144) 
Monneret C 2005 Histone deacetylase inhibitors. European Journal of Medicinal Chemistry 40 1-13. (doi:10.1016/j.ejmech.2004.10.001)

Nebbioso A, Clarke N, Voltz E, Germain E, Ambrosino C, Bontempo P, Alvarez R, Schiavone EM, Ferrara F, Bresciani F et al. 2005 Tumorselective action of HDAC inhibitors involves TRAIL induction in acute myeloid leukemia cells. Nature Medicine 11 77-84. (doi:10. 1038/nm1161)

Nebbioso A, Manzo F, Miceli M, Conte M, Manente L, Baldi A, De Luca A, Rotili D, Valente S, Mai A et al. 2009 Selective class II HDAC inhibitors impair myogenesis by modulating the stability and activity of HDAC-MEF2 complexes. EMBO Reports 10 776-782. (doi:10.1038/embor.2009.88)

Nesto RW, Bell D, Bonow RO, Fonseca V, Grundy SM, Horton ES, Le Winter M, Porte D, Semenkovich CF, Smith S et al. 2003 Thiazolidinedione use, fluid retention, and congestive heart failure: a consensus statement from the American Heart Association and American Diabetes Association. October 7, 2003. Circulation 108 2941-2948. (doi:10.1161/01.CIR.0000103683.99399.7E)

Nielsen R, Pedersen TA, Hagenbeek D, Moulos P, Siersbaek R, Megens E, Denissov S, Børgesen M, Francoijs KJ, Mandrup S et al. 2008 Genome-wide profiling of PPARgamma:RXR and RNA polymerase II occupancy reveals temporal activation of distinct metabolic pathways and changes in RXR dimer composition during adipogenesis. Genes and Development 22 2953-2967. (doi:10.1101/ gad.501108)

Palazzo A, Ackerman B \& Gundersen GG 2003 Cell biology: tubulin acetylation and cell motility. Nature 421 230. (doi:10.1038/421230a)

Qiao L, Schaack J \& Shao J 2006 Suppression of adiponectin gene expression by histone deacetylase inhibitor valproic acid. Endocrinology 147 865-874. (doi:10.1210/en.2005-1030)

Rangwala SM \& Lazar MA 2000 Transcriptional control of adipogenesis. Annual Review of Nutrition 20 535-559. (doi:10.1146/annurev. nutr.20.1.535)

Rochette-Egly C \& Chambon P 2001 F9 embryocarcinoma cells: a cell autonomous model to study the functional selectivity of RARs and RXRs in retinoid signaling. Histology and Histopathology 16 909-922.

Rodgers JT, Lerin C, Haas W, Gygi SP, Spiegelman BM \& Puigserver P 2005 Nutrient control of glucose homeostasis through a complex of PGC-1alpha and SIRT1. Nature 434 113-118. (doi:10.1038/ nature03354)
Valenzuela-Fernández A, Román Cabrero J, Serrador JM \& SánchezMadrid F 2008 HDAC6: a key regulator of cytoskeleton, cell migration and cell-cell interactions. Trends in Cell Biology 18 291-297. (doi:10.1016/j.tcb.2008.04.003)

Vega RB, Matsuda K, Oh J, Barbosa AC, Yang X, Meadows E, McAnallyJ, Pomajzl C, Shelton JM, Richardson JA et al. 2004 Histone deacetylase 4 controls chondrocyte hypertrophy during skeletogenesis. Cell 119 555-566. (doi:10.1016/j.cell.2004.10.024)

Verdin E, Dequiedt F \& Kasler HG 2003 Class II histone deacetylases: versatile regulators. Trends in Genetics 19 286-293. (doi:10.1016/ S0168-9525(03) 00073-8)

Wang C, Fu M, Angeletti RH, Siconolfi-Baez L, Rutens AT, Albanese C, Lisanti MP, Katzenellenbogen BS, Kato S, Hopp T et al. 2001 Direct acetylation of the estrogen receptor alpha hinge region by p300 regulates transactivation and hormone sensitivity. Journal of Biological Chemistry 276 18375-18383. (doi:10.1074/jbc. M100800200)

Weiler-Guettler H, Yu K, Soff G, Gudas LJ \& Rosenberg RD 1992 Thrombomodulin gene regulation by cAMP and retinoic acid in F9 embryonal carcinoma cells. PNAS 89 2155-2159. (doi:10.1073/ pnas.89.6.2155)

Yang XJ \& Gregoire S 2005 Class II histone deacetylases: from sequence to function, regulation, and clinical implication. Molecular and Cellular Biology 25 2873-2884. (doi:10.1128/MCB.25.8.28732884.2005)

Yoo CB \& Jones PA 2006 Epigenetic therapy of cancer: past, present and future. Nature Reviews. Drug Discovery 5 37-50. (doi:10.1038/ $\operatorname{nrd1930)}$

Zhang Y, Li N, Caron C, Matthias G, Hess D, Khochbin S \& Matthias P 2003 HDAC-6 interacts with and deacetylates tubulin and microtubules in vivo. EMBO Journal 22 1168-1179. (doi:10.1093/ emboj/cdg115)

Zhang H, Zhang A, Kohan DE, Nelson RD, Gonzalez FJ \& Yang T 2005 Collecting duct-specific deletion of peroxisome proliferatoractivated receptor gamma blocks thiazolidinedione-induced fluid retention. PNAS 102 9406-9411. (doi:10.1073/pnas. 0501744102)

Received in final form 1 July 2010

Accepted 16 July 2010

Made available online as an Accepted Preprint 16 July 2010 